\title{
Tuberculose miliar - relato de caso
}

\author{
Miliary tuberculosis - case report \\ Vitorino Modesto dos Sontos, Marlene Antônio dos Reis, Marco Antonio Bonatti \\ Resende, Jenner Arruda Modesto dos Santos, Alessandra Iamanjara \\ Bernardini e Luciono Barboza de Souza
}

Resumo Relata-se caso da forma miliar generalizada da infecção tuberculosa, em homem de 80 anos não portador da síndrome da imunodeficiência adquirida (SIDA) cujo óbito decorreu de progressiva disseminação hematogênica, semelhante a casos da era pré-antibiótica. Enfatiza-se a associação com estados de subnutrição e imunodepressão, a dificuldade na abordagem clínica e a importância da necropsia para estabelecer o diagnóstico da disseminação miliar hematogênica crônica ou críptica.

Palavras-chaves: Tuberculose miliar generalizada. Tuberculose hematogênica crônica. Necropsia.

\begin{abstract}
This is a case report of generalized miliary tuberculous infection in a 80-year old white male without the acquired immunodeficiency syndrome, whose death was caused by progressive hematogenous seeding similar to those cases of preantibiotic era. The importance of autopsy studies to uncover silent or protean infections specially in cases of cryptic or chronic hematogenous miliary tuberculosis, is emphasized.
\end{abstract}

Key-words: Miliary tuberculosis. Late generalized tuberculosis. Necropsy.

Disciplina de Patologia Geral, Curso de Pós-Graduação em Patologia e Departamento de Clínica Médica da Faculdade de Medicina do Triângulo Mineiro, Uberaba, MG.

Endereço para correspondência: Prof. Vitorino Modesto dos Santos. Alameda da República 64. Recanto das Torres, 38057-020 Uberaba, MG.

Recebido para publicação em 30/04/97. 
As dificuldades para controlar a tuberculose, associadas à fome e ao subdesenvolvimento, aumentaram com o advento da AIDS na última década. Pelo fato de apresentar quadros clínicos multivariados, em geral, diagnosticar a forma miliar da doença constitui grande desafio à argúcia dos clínicos 6 . Infecções tuberculosas generalizadas usualmente causam alterações inespecíficas nos exames laboratoriais de rotina1 257 e podem não ser evidenciadas pela radiografia de tórax 811 . Na maioria dos casos é diagnosticada pelo exame de material obtido por punções, procedimentos cirúrgicos ou necropsias 1214 . Tem sido freqüente sua associação com estados de imunodepressão, especialmente nas fases mais avançadas da AIDS. Apesar do período de internação de apenas três dias ter dificultado o diagnóstico in vivo, foi possível realizar necropsia de paciente imunodeprimido, não-aidético, com tuberculose miliar generalizada. A publicação deste caso visa realçar o papel da necropsia para detectar casos de tuberculose miliar, especialmente quando não diagnosticada com recursos clínicos.

\section{RELATO DO CASO}

Homem branco, 80 anos, lavrador, solteiro, natural de Sacramento, MG, procedente de Uberaba, MG; internado no Hospital Escola da FMTM em 22/08/95.

Anamnese. Doente há cerca de 15 dias, queixava-se apenas de inapetência, febre $\left(38^{\circ} \mathrm{C}\right)$, adinamia e dor nas pernas. Episódios febris esporádicos há vários anos. Referia pneumonia, há 17 anos. Ex-tabagista crônico. Habitou zona rural por 40 anos. Etilista, uso freqüente de "chás caseiros" (infusão em aguardente). Antecedentes de tuberculose pulmonar: pai falecido em 1939 e irmã tratada em 1950. Exame físico. Mau estado geral, peso $48 \mathrm{~kg}$, altura $1,64 \mathrm{~m}$, mucosas hipocoradas $(+)$, petéquias e equimoses nos membros superiores. Temperatura axilar: $38,3^{\circ} \mathrm{C}$. Tiragem intercostal bilateral e diminuição global do murmúrio vesicular, estertores bolhosos nos terços médio e inferior do pulmão direito. Rítmo cardíaco regular, 72 bpm e hipofonese de bulhas. Tensão arterial $=120 / 70 \mathrm{mmHg}$. Fígado palpável a $2 \mathrm{~cm}$ do rebordo costal direito, indolor, liso e com borda romba. Baço palpável a $1 \mathrm{~cm}$ do rebordo costal esquerdo, indolor, liso e de consistência normal.

Exames complementares. Hemácias $5.030 .000 / \mathrm{mm}^{3}$; hemoglobina $14,2 \mathrm{~g} / \mathrm{dl}$; hematócrito 44\%; volume corpuscular médio $87 \mu 3$; plaquetas $42.000 / \mathrm{mm}^{3}$; leucócitos $1.300 / \mathrm{mm}^{3}$ (bastões 4\%, segmentados $63 \%$, linfócitos $29 \%$ e monócitos 4\%). Mielograma: intensa hipoplasia eritroblástica, com predomínio de policromáticos; discreta pobreza granulocítica, com marcada disgranulocitopoiese; discreta hipocelularidade megacariocítica, com inúmeros grumos plaquetários; série linfohistioplasmocitária normocelular. Albumina 2,9g/dl; globulinas $5,4 \mathrm{~g} / \mathrm{dl}$; sódio $134 \mathrm{mEq} / \mathrm{l}$; potássio $4,5 \mathrm{mEq} / \mathrm{l}$; uréia $86 \mathrm{mg} / \mathrm{dl}$; creatinina 1,6mg/dl; glicose $103 \mathrm{mg} / \mathrm{dl}$; cálcio $7,8 \mathrm{mEq} / \mathrm{l}$; fósforo $4 \mathrm{mEq} / \mathrm{l}$; fosfatase alcalina 318U/l; gama-GT 165U//; desidrogenase lática 2.908U/l; amilase $341 \mathrm{U} / \mathrm{l}$; bilirrubina indireta $0,69 \mathrm{mg} / \mathrm{dl}$; bilirrubina direta $1,17 \mathrm{mg} / \mathrm{dl}$; TGO $352 \mathrm{U} / \mathrm{l}$; TGP $66 \mathrm{U} / \mathrm{l}$; atividade protrombínica $41 \%$; PTTA 1,42; fibrinogênio $700 \mathrm{mg} / \mathrm{dl}$. Teste de Coombs direto e indireto negativos.

Evolução. O paciente recusou a medicação prescrita. Houve piora do estado geral, acentuação da dispnéia e dos estertores. A radiografia do tórax mostrou consolidação no lobo médio. Apresentou insuficiência renal, hiponatremia, elevação de enzimas hepáticas e de amilase, hipoalbuminemia e elevação das globulinas, aumento da desidrogenase lática, diminuição da atividade protrombínica, além de plaquetopenia e leucopenia acentuadas. $O$ óbito ocorreu em 25/08/95, no 3o dia de internação.

Exame anatomopatológico. Tuberculose miliar disseminada, caracterizada por inflamação crônica granulomatosa e necrose caseosa com presença de bacilos álcool-ácido resistentes corados pelo Ziehl-Nielsen, acometendo pulmões, linfonodos hilares, fígado, pâncreas, medula óssea, baço, supra-renais, rins e próstata. Pulmões (direito $710 \mathrm{~g}$; esquerdo $686 \mathrm{~g}$ ), com inúmeros nódulos miliares em todo o parênquima e também subpleurais. Nódulo com necrose caseosa, medindo $3,0 \mathrm{~cm}$ de diâmetro, no ápice esquerdo (Figura 1). Enfisema crônico bilateral, com bolhas de até $5,0 \mathrm{~cm}$ de diâmetro localizadas no ápice esquerdo. Traqueobronquite mucopurulenta. Broncopneumonite aguda bilateral, predominando nas bases. Focos de hemorragia parenquimatosa. Pleurite crônica com aderências apicais. Fígado (1275g), com nódulos miliares disseminados. Pâncreas com focos de inflamação granulomatosa e necrose caseosa. Medula óssea com vários focos de inflamação granulomatosa e necrose caseosa, além de discreta hipocelularidade, especialmente 


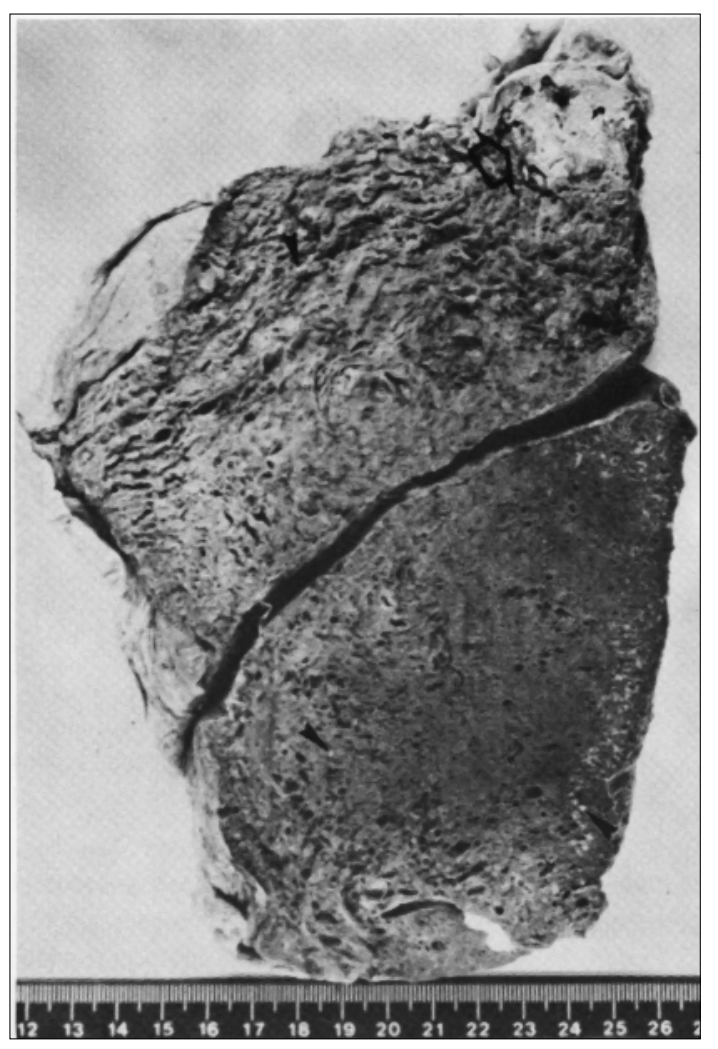

Figura 1 - Superfície de corte do pulmão esquerdo enfisematoso, mostrando nódulo de $3 \mathrm{~cm}$ de diametro com necrose caseosa na região apical (flecha) e nódulos miliares parenquimatosos disseminados (setas). Áreas de broncopneumonite aguda com focos de hemorragia no lobo inferior.

na série megacariocítica. Baço (458g), com nódulos miliares de inflamação granulomatosa e necrose caseosa, além de hiperplasia reacional aguda e polpas difluentes e friáveis. Supra-renais $(15 \mathrm{~g})$ com disseminação miliar e hipotrofia moderada. Rins (direito 157g; esquerdo 115g) com focos de inflamação granulomatosa e necrose caseosa. Próstata com focos de inflamação granulomatosa e necrose caseosa, além de adenocarcinoma moderadamente diferenciado. Encéfalo $(1270 \mathrm{~g})$ com hipotrofia moderada, principalmente dos lobos frontais, congestão difusa acentuada e focos com corpos amiláceos. Arteriosclerose aterosclerótica sistêmica, com formação de placas fibrosadas e calcificadas principalmente na aorta e seus principais ramos. Coração $(288 \mathrm{~g})$ com hipotrofia parda do miocárdio. Testículos com hipotrofia moderada.

\section{DISCUSSÃO}

A presença de infecção tuberculosa disseminada em paciente imunodeprimido, com acentuada linfopenia $\left(377 / \mathrm{mm}^{3}\right)$ e subnutrição (índice de massa corporal $=17,85 \mathrm{~kg} / \mathrm{m}^{2}$ ), levantou a possibilidade de concomitância com a SIDA. A ausência de infecções oportunísticas, a demonstração do clássico padrão inflamatório exsudativo-necrosante, a formação de granulomas caseosos com células gigantes típicas e a pobreza de bacilos nas lesões, corroboram com a negatividade da pesquisa de anticorpos para o HIV, pelo método ELISA, realizado em soro obtido durante a necropsia (título $=0,010 \mathrm{ng} / \mathrm{ml}$ e cut off $=0,115 \mathrm{ng} / \mathrm{ml}$ ).

Disseminação miliar, inclusive do tipo anérgica, pode ocorrer na ausência de infecção pelo HIV, quando a tuberculose se associa com outras causas de imunodepressão como insuficiência renal, diabetes mellitus, idade avançada, etilismo, subnutrição, doença pulmonar obstrutiva crônica, hemopatias e tumores malígnos 3910 16. Nosso paciente tinha 80anos, abusava de bebidas alcoólicas, estava subnutrido, era portador de enfisema pulmonar crônico e de câncer na próstata.

O presente caso serve para ilustrar que, mesmo na ausência de SIDA, uma intensa imunodepressão pode conduzir à disseminação miliar da tuberculose, evoluindo para o óbito como geralmente ocorria no curso "galopante" de infecções graves na era pré-antibiótica16. Acreditamos que, através da experiência estribada em estudos detalhados de necropsia, os médicos mais jovens estarão melhor capacitados a identificar e curar uma maior parcela de casos, incluindo aqueles com tuberculose miliar críptica ou anérgica, em que o diagnóstico clínico se torna mais difícil13 1516.

\section{REFERÊNCIAS BIBLIOGRÁFICAS}

1. Cameron SJ. Tuberculosis and the blood: A special relationship. Tubercle 55:55-72, 1974.

2. Chan CHS, Chan YK, Shek ACC, Mak TWL, Lui SF, Lai KN. Severe hypercalcemia associated with miliary tuberculosis. Journal of Tropical Medicine and Hygiene 97:180-182, 1994.

3. Dahmash NS, Fayed DF, Chowdhrury MNH, Arora SC. Diagnostic challenge of tuberculosis of the 
elderly in hospital: experience at a University hospital in Saudi Arabia. The Journal of Infection 31:93-97, 1995.

4. Eide FF, Gean AD, So YT. Clinical and radiographic findings in disseminated tuberculosis of the brain. Neurology 43:1427-1429, 1993.

5. Eliopoulus G, Vaiopoulus G, Kittas C, Fessas P. Tuberculosis associated hemophagocityc syndrome complicated with severe bone marrow failure and disseminated intravascular coagulation. Nouvelle Revue Française d'Hematologie 34:273-276, 1992.

6. Grieco MH, Chmel H. Acute disseminated tuberculosis as a diagnostic problem: A clinical study based on twenty-eight cases. American Review of Respiratory Disease 109:554-560, 1974.

7. Hussain W, Harrison R, Hubscher S, Neuberger J. Fulminant hepatic failure caused by tuberculosis. Gut 36:792-794, 1995.

8. Jamieson DH, Cremin BJ. High-resolution CT of the lungs in acute disseminated tuberculosis and a pediatric radiology perspective of the term "miliary". Pediatric Radiology 23:380-383, 1993.

9. Jones BE, Young SMM, Antoniskis D, Davidson RT, Kramer F, Barnes PF. Relationship of the manifestations of tuberculosis to CD4 cell counts in patients with human immunodeficiency virus infection. American Review of Respiratory Disease 148:1292-1297, 1993.
10. Kinoshita M, Ichikawa Y, Koga H, Sumita S, Oizumi K. Re-evaluation of bone marrow aspiration in the diagnosis of miliary tuberculosis. Chest 106:690-692, 1994.

11. Kwong JS, Carignan S, Kang E-Y, Müller NL, FitzGerald JM. Miliary tuberculosis. Diagnostic accuracy of chest radiography. Chest 110:339-342, 1996.

12. Optican RJ, Ost A, Ravin CE. High-resolution computed tomography in the diagnosis of miliary tuberculosis. Chest 102:941-943, 1992.

13. Santos VM, Brasil MHS. Tuberculose miliar. Estudo clínico-patológico de 6 casos. Brasília Médica 4:82-84, 1970.

14. Selby C, Thomson D, Leitch AG. Death in notified cases of tuberculosis in Edinburgh: 1983-1992. Respiratory Medicine 89:369-371, 1995.

15. Sharma SK, Mohan A, Pande JN, Prasad KL, Gupta AK.Clinical profile, laboratory characteristics and outcome in miliary tuberculosis. Quarterly Journal of Medicine 88:29-37, 1995.

16. Slavin RE, Walsh TJ, Pollack AD. Late generalized tuberculosis: A clinical pathologic analysis of 100 cases in the preantibiotic and antibiotic eras. Medicine 59:352-366, 1980. 